\title{
revivista educação
}

DOI: 10.33947/1980-6469-v15n1-4013

\section{REFLEXÕES SOBRE O BULLYING NA EDUCAÇÃO INFANTIL \\ REFLECTIONS ON BULLYING IN CHILD EDUCATION}

Fernanda Alves da Silva ${ }^{1}$

\section{RESUMO}

O presente artigo faz uma reflexão sobre o bullying apresentando o seu significado e de que forma pode estar presente na educação infantil, perpassa pela cultura de paz como forma de ação pedagógica, acredita na transformação da cultura de uma sociedade, na qual cada vez mais valorizam atitudes como respeito, educação, diálogo, cooperação e ética para o desenvolvimento das relações humanas. Apresentando algumas das legislações brasileiras de ações antibullying em nível federal e estatual

PALAVRAS-CHAVE: Bullying. Educação Infantil. Cultura de paz. Legislação

\section{ABSTRACT}

The present article makes a reflection about bullying presenting its meaning and how it can be present on child education, which passes in the peace culture as a way of pedagogical action, it believes on the transformation of a culture of a society, which each time appreciates more attitudes as respect, education, dialogue, cooperation and ethics for the development of human relation. Presenting some Brazilian legislations of no bullying action on federal and state level.

KEYWORDS: Bullying. Child Education. Peace Culture. Legislations

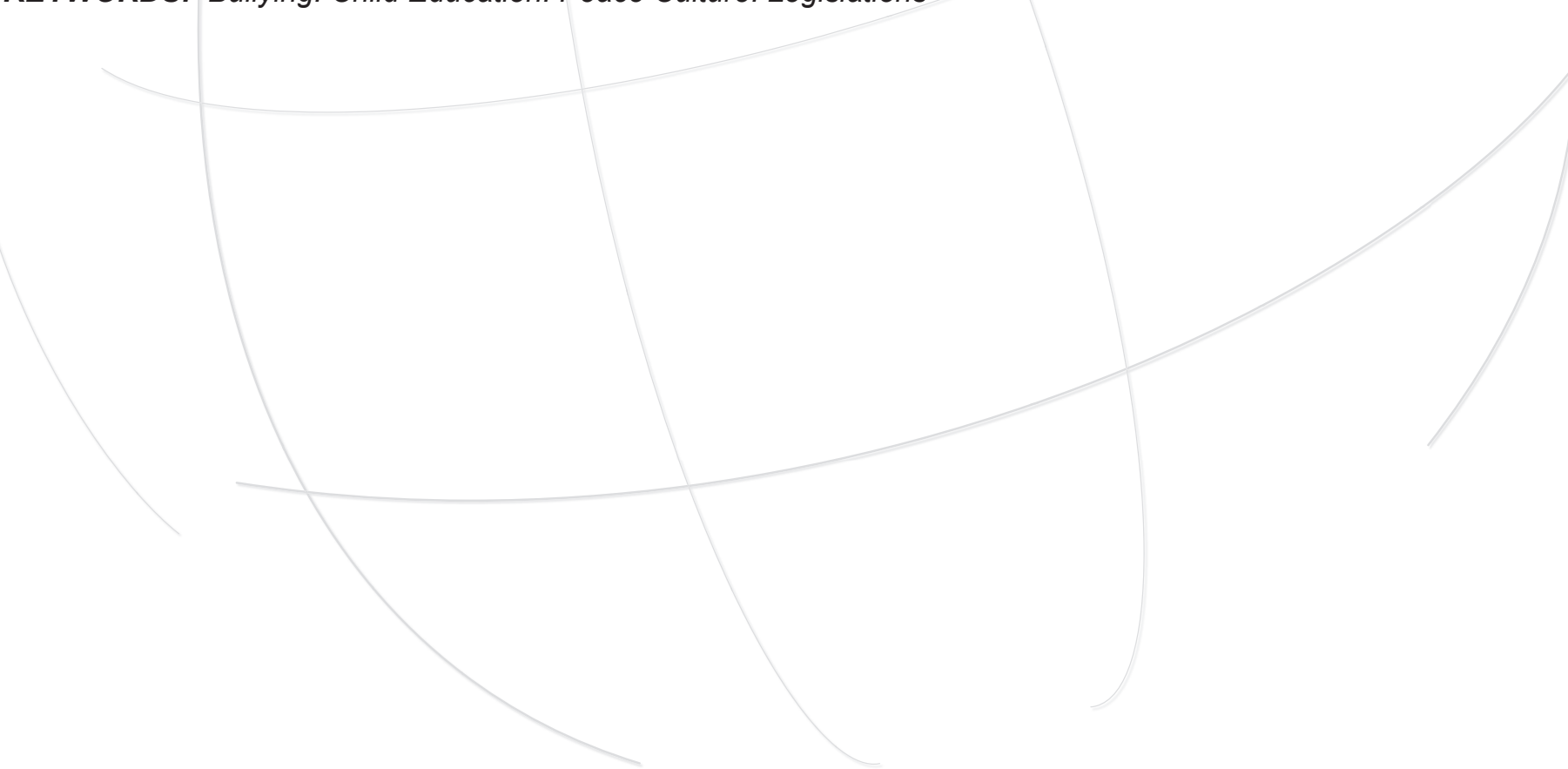

1 Professora de Educação Infantil na Prefeitura Municipal de Guarulhos. Graduação em Pedagogia pela Universidade Federal de São Paulo (UNIFESP). 


\section{Introdução}

$\mathrm{O}$ artigo tem por objetivo fazer algumas reflexões para que os profissionais da educação possam compreender melhor a questão do bullying na educação infantil buscando entender o que é o bullying, a partir de qual idade a criança pode ter um comportamento baseado no bullying e quais são as legislações governamentais brasileiras de ações antibullying.

Universalmente a palavra bullying de origem inglesa que vem do bully que significa valente ou brigão, é compreendida como um conjunto de comportamentos agressivos sendo intencionais, verbais ou físicos, em português não tem uma definição, porém a palavra é assimilada ao comportamento de intimidação, humiIhação e ameaça.

Chalita (2008, p. 81) ressalta que "o fenômeno bullying não escolhe classe social ou econômica, escola pública ou privada, ensino fundamental ou médio, área rural ou urbana. Está presente em grupos de crianças e jovens, em escolas de países e culturas diferentes."

Para ser considerado bullying não podemos deixar de destacar que o comportamento agressivo seja ele verbal ou físico deve ser repetitivo. No cotidiano escolar devemos ter muito cuidado para não normatizar uma ação ou comportamento entre crianças o chamado "é coisa de criança ou é normal entre as crianças"

Segundo Beane (2010, p.17) devemos saber diferenciar o bullying de um conflito normal, e que alguns conflitos são partes da vida desde que não fira o outro podendo ser até de ajuda para a vida.

Para isso é necessária uma boa observação dos adultos, uma escuta sensível e principalmente o dialogo, para que seja verificado o comportamento das crianças e se realmente se excedeu os limites do conflito que é considerado normal e não tratando do assunto como uma simples brincadeira.

Existem duas formas de praticar o bullying de forma indireta, mais difícil de detectar e a direta que inclui agressões físicas como chutes e empurrões, verbais através de xingamentos e apelidos e a psicológica a qual o autor intimida, constrange e coloca medo.

Para William Voors $(2000$, p.5) o adulto deve sempre observar se existe o sentimento descrito abaixo entre o autor e a vítima do bullying:
Deve haver sentimentos contrastantes entre a criança que pratica o bullying e seu alvo como resultado do episódio de bullying. A criança que pratica o bullying pode se sentir excitada, poderosa ou achando graça depois do episódio de bullying, enquanto que aquela que sofreu o bullying se sente amedrontada, embaraçada ou ferida

Como educadores devemos estar atentos a manifestações de comportamento da vítima do bullying, como isolamento e queda do rendimento escolar. De acordo com a Revista Nova Escola referente ao tema, a Associação Brasileira Multiprofissional de Proteção à Infância e Adolescência (ABRAPIA) revela que 41,6\% das vítimas nunca procuraram ajuda ou falaram sobre o problema, nem mesmo com os colegas.

Embora o bullying seja muito mais praticado entre os adolescentes devido aos desvios comportamentais que são comuns nessa fase, devemos ficar atentos na educação infantil, pois é nela que a formação inicial começa.

\section{Bullying na educação infantil}

Na educação infantil é fato que as crianças pequenas briguem entre si, seja para disputar algo ou alguém. E essas condutas das crianças menores de seis anos devem ser encaradas com naturalidade, pois, a criança de 0 a 6 anos está na fase do egocentrismo. Como podemos averiguar no artigo $O$ educador $e$ a moralidade infantil numa perspectiva construtivista de Telma Vinha (1999, p.21), que crianças de seis anos são egocêntricas e incapazes de coordenar pontos de vista diferentes, de se colocar no lugar do outro.

De acordo com a teoria de Piaget a criança passa por estágios ou etapas de desenvolvimento e precisa de estímulos para construir seu desenvolvimento cognitivo. Para entendermos o significado de duas das etapas do desenvolvimento Camargo (2009) as descreve:

Na primeira etapa a sensório-motora, as crianças agem por meio de reflexos neurológicos, participam do mundo pelos sentidos de forma direta e objetiva, sem formular reflexões e pensamentos, conhecem o mundo pelos sentidos, levando os objetos até a boca e prestam atenção em cada ruído ocorrido a sua vol- 
ta, desenvolvem-se emocionalmente e criam noção do tempo-espaço e objeto por meio da ação.

Na segunda etapa pré-operatório, ocorre o despertar da comunicação, a criança ganha, ano a ano, um vocabulário cada vez mais extenso, facilitando a socialização, conhece e gosta de brincar com o outro, interagir e se comunicar, há um avanço no desenvolvimento cognitivo, social e afetivo em decorrência da aquisição da linguagem.

Segundo os estágios de Piaget, as crianças de quatro e cinco anos estão na fase pré-operatória, e nesta idade, começam a "abandonar" o egocentrismo e começam a socializar-se, mostrando também maior consistência em seus sentimentos em relação a algo e/ou alguém, ou seja, gostar ou não gostar. Sendo assim é nesse período que podem aparecer os conflitos e as crianças podem demonstrar comportamentos de discriminação, provocações ou até mesmo comportamentos agressivos que são praticados, por exemplo, de forma repetida e com o mesmo alvo.

As pesquisas sobre bullying são feitas normalmente e em sua grande maioria nas escolas de ensino fundamental, porém o bullying é encontrado em todos os espaços de uma escola, em família, em residências, onde existir pessoas e houver convivência.

A criança como sujeito do seu aprendizado se relaciona e convive com o outro, sendo assim aprende com outro, pois a todo momento recebe informações e influências dos sujeitos de seu convívio, logo se uma criança tem convívio com pessoas que praticam o bullying a mesma poderá desenvolver esse comportamento, é nesse momento que o adulto deve estar atento para intervir.

Atitudes que passam despercebidas pelos adultos, que podem anteceder o bullying propriamente dito, facilitam problemas futuros, tanto para as vítimas quanto para os agressores, dentro e fora da escola.

Apesar do bullying na educação infantil ser pouco pesquisado e ainda ser um assunto delicado por se tratar de crianças pequenas, devemos estar atentos, não é porque pouco se faz pesquisas em escolas de educação infantil que se pode afirmar que ele não exista.

O educador ao notar agressões deve interferir desde cedo. De acordo com Fante e Pedra (2008, p.99):
Entre os 2 e os 3 anos, as crianças precisam ter alguém que intervenha a fim de conter adequadamente o impulso e a ânsia que o provoca. Caso isso não aconteça, esse tipo de comportamento passa a fazer parte do seu repertório comportamental. Uma vez adotado esse comportamento, muitas crianças passam a desempenhá-lo em suas relações sociais, através de atitudes intimatórias, abusivas e agressivas, como forma de manipular e conseguir seus intentos.

Portanto, os educadores devem ficar atentos, para que na educação infantil se construa saberes importantes para as crianças, possibilitando o desenvolvimento das crianças de respeito e solidariedade ao próximo.

A escola é um espaço onde tem por objetivo a formação de cidadãos e um lugar para se desenvolver atitudes, para tanto é necessário que educadores sejam pessoas humanas capazes de compreender e ajudar o outro, dessa forma podem desenvolver atitudes de respeito e solidariedade nos educandos.

O bullying no ambiente escolar existe e precisa ser combatido, nos tempos atuais nota-se que as pessoas não sabem resolver conflitos e acabam agredindo as outras pessoas. Por diversas vezes frases são utilizadas como forma de resolver o conflito, porém somente aumentam uma delas por exemplo seria "filho você não deve apanhar na escola, se baterem, bata também". Neste momento que a escola se posiciona e interfere procurando desenvolver questões como respeito, humildade, cooperação e diálogo.

Nos últimos anos é crescente o movimento de uma educação por cultura de paz, que visa o respeito a vida, a diversidade, rejeitando a violência e ensinando os educandos a ouvirem para serem ouvidos e compreendidos, fortalecendo os direitos humanos.

A Organização das Nações Unidas (ONU) definiu cultura de paz na Declaração e Programa de Ação sobre uma Cultura de Paz, em 13 de setembro de 1999:

Uma Cultura de Paz é um conjunto de valores, atitudes, tradições, comportamentos e estilos de vida baseados: No respeito à vida, no fim da violência e na promoção e prática da não-violência por meio da educação, do diálogo e da coopera- 
ção; No pleno respeito e na promoção de todos os direitos humanos e liberdades fundamentais; No compromisso com a solução pacífica dos conflitos; Nos esforços para satisfazer as necessidades de desenvolvimento e proteção do meio -ambiente para as gerações presente e futuras; No respeito e fomento à igualdade de direitos $e$ oportunidades de mulheres e homens; No respeito e fomento ao direito de todas as pessoas à liberdade de expressão, opinião e informação; $\mathrm{Na}$ adesão aos princípios de liberdade, justiça, democracia, tolerância, solidariedade, cooperação, pluralismo, diversidade cultural, diálogo e entendimento em todos os níveis da sociedade e entre as nações; e animados por uma atmosfera nacional e internacional que favoreça a paz

Para que ocorra uma mudança de violência para a cultura de paz é necessário a transformação, ou seja uma mudança de cultura na sociedade e a instituição mais abrangente é a escola, pois Vygotsky (2005) sustenta que a cultura é um aspecto primordial nas transformações sociais:

Nesse processo, o indivíduo ao mesmo tempo em que internaliza as formas culturais, as transforma e intervém em seu meio. Desse ponto de vista, o homem é visto como alguém que transforma e é transformado nas relações produzidas em uma determinada cultura. É, portanto na relação dialética com o mundo que o sujeito se constitui e se desenvolve (VYGOTSKY apud REGO, 2005, p. 5).

Para que essa cultura de paz aconteça, faz-se necessário que desde cedo lá na educação infantil a criança conviva em ambiente não violento, ensinando o diálogo, a solidariedade e a empatia.

\section{Legislações brasileiras de combate ao bullying}

No portal do MEC temos a informação que um a cada dez estudantes brasileiros é vítima de bullying. O dado foi divulgado pelo Programa Internacional de Avaliação de Estudantes (Pisa) 2015.

No Brasil desde 2015 temos a lei n. ${ }^{0} 13.185$, de
06 de novembro de 2015, que Institui o Programa de Combate à Intimidação Sistemática (Bullying), apresentando os seguintes artigos:

Art. 1 Fica instituído o Programa de Combate à Intimidação Sistemática (Bullying) em todo o território nacional.

$\S 1^{\circ}$ No contexto e para os fins desta Lei, considera-se intimidação sistemática (bullying) todo ato de violência física ou psicológica, intencional e repetitivo que ocorre sem motivação evidente, praticado por indivíduo ou grupo, contra uma ou mais pessoas, com o objetivo de intimidá-la ou agredi-la, causando dor e angústia à vítima, em uma relação de desequilíbrio de poder entre as partes envolvidas.

$\S$ 2ㅇ O Programa instituído no caput poderá fundamentar as ações do Ministério da Educação e das Secretarias Estaduais e Municipais de Educação, bem como de outros órgãos, aos quais a matéria diz respeito.

Art. 2ㅇ Caracteriza-se a intimidação sistemática (bullying) quando há violência física ou psicológica em atos de intimidação, humilhação ou discriminação e, ainda:

I - ataques físicos;

II - insultos pessoais;

III - comentários sistemáticos e apelidos pejorativos;

IV - ameaças por quaisquer meios;

$\mathrm{V}$ - grafites depreciativos;

VI - expressões preconceituosas;

VII - isolamento social consciente e premeditado;

VIII - pilhérias.

Parágrafo único. Há intimidação sistemática na rede mundial de computadores (cyberbullying), quando se usarem os instrumentos que lhe são próprios para depreciar, incitar a violência, adulterar fotos e dados pessoais com o intuito de criar meios de constrangimento psicossocial.

Art. 3o A intimidação sistemática (bullying) pode ser classificada, conforme as ações praticadas, como:

I - verbal: insultar, xingar e apelidar pejorativamente; 
II - moral: difamar, caluniar, disseminar rumores;

III - sexual: assediar, induzir e/ou abusar;

IV - social: ignorar, isolar e excluir;

V - psicológica: perseguir, amedrontar, aterrorizar, intimidar, dominar, manipular, chantagear e infernizar;

VI - físico: socar, chutar, bater;

VII - material: furtar, roubar, destruir pertences de outrem;

VIII - virtual: depreciar, enviar mensagens intrusivas da intimidade, enviar ou adulterar fotos e dados pessoais que resultem em sofrimento ou com o intuito de criar meios de constrangimento psicológico e social.

Art. 4 Constituem objetivos do Programa referido no caput do art. 10:

I - prevenir e combater a prática da intimidação sistemática (bullying) em toda a sociedade;

II - capacitar docentes e equipes pedagógicas para a implementação das ações de discussão, prevenção, orientação e solução do problema; III - implementar e disseminar campanhas de educação, conscientização e informação;

IV - instituir práticas de conduta e orientação de pais, familiares e responsáveis diante da identificação de vítimas e agressores;

V - dar assistência psicológica, social e jurídica às vítimas e aos agressores;

$\mathrm{VI}$ - integrar os meios de comunicação de massa com as escolas e a sociedade, como forma de identificação e conscientização do problema e forma de preveni-lo e combatê-lo;

VII - promover a cidadania, a capacidade empática e o respeito a terceiros, nos marcos de uma cultura de paz e tolerância mútua;

VIII - evitar, tanto quanto possível, a punição dos agressores, privilegiando mecanismos e instrumentos alternativos que promovam a efetiva responsabilização e a mudança de comportamento hostil;

IX - promover medidas de conscientização, prevenção e combate a todos os tipos de violência, com ênfase nas práticas recorrentes de intimidação sistemática (bullying), ou constrangimento físico e psicológico, cometidas por alunos, pro- fessores e outros profissionais integrantes de escola e de comunidade escolar.

Art. 5o É dever do estabelecimento de ensino, dos clubes e das agremiações recreativas assegurar medidas de conscientização, prevenção, diagnose e combate à violência e à intimidação sistemática (bullying).

Art. 6o Serão produzidos e publicados relatórios bimestrais das ocorrências de intimidação sistemática (bullying) nos Estados e Municípios para planejamento das ações.

Art. 7응 Os entes federados poderão firmar convênios e estabelecer parcerias para a implementação e a correta execução dos objetivos e diretrizes do Programa instituído por esta Lei.

Art. 8 Esta Lei entra em vigor após decorridos 90 (noventa) dias da data de sua publicação oficial.

Segundo uma pesquisa apresentada no artigo Legislação contra o Bullying: uma busca para resolver o problema, dos vinte e sete estados brasileiros, incluindo o Distrito Federal, dezenove possuem legislação antibullying aprovada. Quanto às disposições das leis encontram-se algumas diferenças. No Distrito Federal (Lei 4.837, 2012) e nos Estados do Mato Grosso (Lei 9.724, 2012), Maranhão (Lei 9.297, 2010), Pernambuco (Lei 13.995, 2009) e Goiás (Lei 17.151, 2010) as leis indicam que se constituam medidas de prevenção, conscientização e enfrentamento do bullying escolar em seus respectivos sistemas de ensino. As leis dos Estados do Amapá (Lei 1.527, 2010), Paraná (Lei 17.335, 2012), Santa Catarina (Lei 14.651, 2009), Mato Grosso do Sul (Lei 3.887, 2010), Ceará (Lei 14.754, 2010) e Rondônia (Lei 2621, 2011) referem-se à criação de programa de prevenção e combate ao bullying nas escolas. Os Estados do Rio Grande do Sul (Lei 13.474, 2010), Sergipe (Lei 7.055, 2010) e Piauí (Lei 6.076, 2011) determinam a elaboração de políticas antibullying. Em quatro estados, Rondônia (Lei 2590, 2011), Amazonas (Lei 110, 2011), Alagoas (Lei 7.269, 2011) e Espírito Santo (Lei 9.653, 2011), há leis que decretam um dia ou semana para a prevenção e combate ao bullying. No Ceará, a Lei 14.943 (2011) institui o sistema de disk-denúncia para casos 
de bullying. A Lei 9.858 (2012) do Estado da Paraíba trata da penalização às escolas públicas e privadas quando verificada a prática de bullying. No Estado do Rio de Janeiro, a Lei 5.824 (2010) aponta para notificação compulsória de violência contra crianças quando atendidas nos serviços de educação e saúde públicos do estado.

Nota-se que em diversos estados existem leis que procuram ações de combate ao bullying no ambiente escolar, porém não podemos deixar de ressaltar que somente a imposição da lei não combate ao bullying, por isso que dentre algumas leis a ações a serem desenvolvidas para políticas antibullying.

No ano de 2018 foi sancionada a lei n. ${ }^{\circ} 13.663$, de 14 de maio de 2018 que altera o art. 12 da Lei $n^{\circ}$ 9.394, de 20 de dezembro de 1996, para incluir a promoção de medidas de conscientização, de prevenção e de combate a todos os tipos de violência e a promoção da cultura de paz entre as incumbências dos estabelecimentos de ensino.

Para se construir uma sociedade consciente precisamos de leis e ações e principalmente relembrar das palavras de Freire (2006, p.391) "precisamos desde a mais tenra idade formar as crianças para a "cultura da Paz", que necessita desvelar e não esconder, com criticidade ética, a tolerância com o diferente, o espírito de justiça e de solidariedade".

\section{Considerações finais}

Diante das reflexões postas podemos notar que o bullying está presente em todo contexto que houver socialização das pessoas, que é necessário que os educadores compreendam bem o termo, o significado e o impacto que este tipo de comportamento pode causar. Observar que o bullying se faz presente tanto da forma direta como indireta e que as mais comuns são as verbais e psicológicas, que os educadores devem estar atentos e preparados para qualquer manifestação de conflito e principalmente para o bullying.

Com um bom trabalho pedagógico baseado no desenvolvimento de atitudes e da cultura de paz podemos combater o bullying desde a tenra infância, podendo assim construir e/ou transformar uma sociedade, mostrando que a sociedade é construída de maneira coletiva e aprendendo que:

Respeitar alguém significa respeitar sua individualidade, suas formas de expressão e imagem, suas origens, suas escolhas, suas opiniões, seus limites e seus sentimentos. Respeitar não implica em concordar com outro ou elogiar qualquer tipo de conduta. Significa não ter o direito de desqualificar, menosprezar, ridicularizar, oprimir e/ou impor. (SERRÃO; BALLEIRO, 1999, p. 32).

Ao observar as legislações brasileiras podemos notar que poucas auxiliam as instituições escolares, mas não podemos deixar de notar o esforço para qual o poder publico tem para com os programas de diagnostico e combate para com o bullying.

Os profissionais da educação devem se conscientizar das responsabilidades perante o combate ao bullying, procurado conhecer as políticas publicas para o mesmo e promover ações eficazes dentro da sua realidade e comunidade escolar.

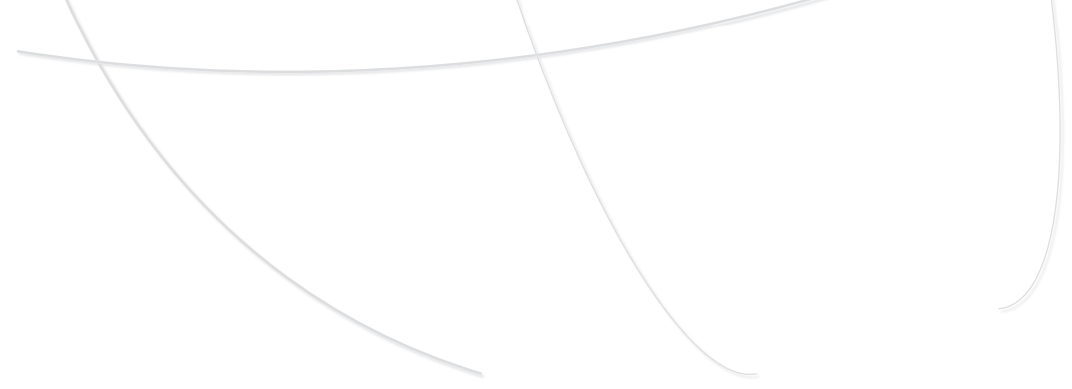




\section{REFERÊNCIAS}

BEANE, Allan. Proteja seu filho do bullying: impeça que ele maltrate os colegas ou seja maltratado por eles. Tradução: Débora Guimarães Isidoro. Rio de Janeiro: Ed. Bestseller, 2010.

BRASIL. Lei n. 13.185 , de 6 de novembro de 2015. Institui o Programa de Combate à Intimidação Sistemática (Bullying). Disponível em: http://www. planalto.gov.br/ccivil_03/Ato2015-2018/2015/Lei/ L13185.htm. Acesso em: 09 mar. 2019.

CAMARGO, Carolina Giannoni. Brincadeiras que fazem chorar!: introdução ao fenômeno Bullying. São Paulo: All Print, 2009.

CHALITA, Gabriel. Pedagogia da amizade -bullying: o sofrimento das vítimas e dos agressores. São Paulo: Gente, 2008.

FANTE, Cléo; PEDRA, José Augusto. Bullying Escolar Perguntas e Respostas. São Paulo: Artmed, 2008.

FREIRE. N. M. B. et al. Educação Para a Paz e a Tolerância: fundamentos teóricos e Prática educacional. São Paulo: Mercado das Letras, 2006.

FRICK, Loriane Trombini. Legislação contra o Bullying: uma Busca para resolver o problema. Disponível em: http://educere.bruc.com.br/ANAIS2013/ pdf/9929 5732.pdf. Acesso em: 09 mar. 2019.
PIAGET, Jean; INHELDER, Bärbel. A psicologia da criança. São Paulo: DIFEL, 1982.

NOVA ESCOLA. Quais as especificidades para lidar com o bullying na Educação Infantil?. Revista Nova Escola [on-line], 01 dezembro de 2010. Disponivel em: https://novaescola.org.br/conteudo/115/ bullying-como-lidar-conflitos-educacao-infantil. Acesso em: 01 mar. 2019.

REGO, T. C. A origem da singularidade do ser humano. Análise das hipóteses de educadores à luz da perspectiva de Vygotsky. Disponível em: http:// www.propp.ufms.br/ppgedu/geppe/artigtereza.htm. Acesso em: 07 mar. 2019.

SERRÃO, M; BALEEIRO, M. C. Aprendendo a ser e a conviver. $2^{\text {a }}$ ed. São Paulo: FTD, 1999.

VINHA, Telma Pileggi. O educador e a moralidade infantil numa perspectiva construtivista. Revista do Cogeime, n. 14, jul,1999. Disponível em: https://www. redemetodista.edu.br/revistas/revistas-cogeime/index. php/COGEIME/article/view/506/459.

Acesso em: 07 mar. 2019.

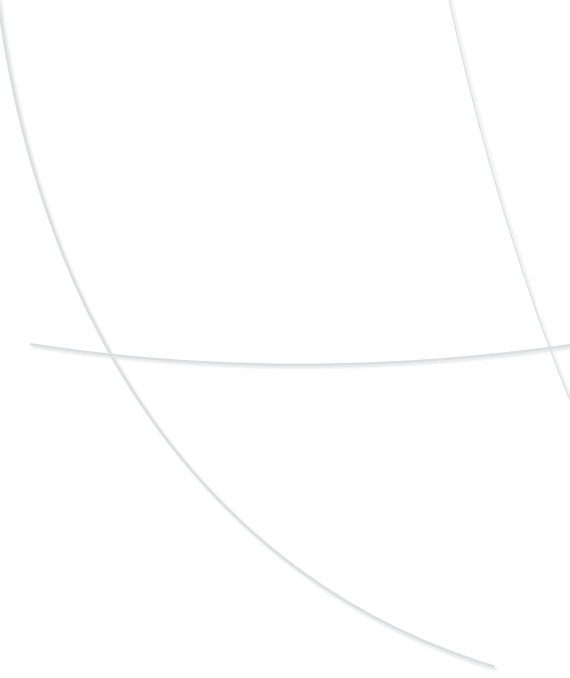

